\title{
Trim Optimizations of an Adaptive Tailless Aircraft with Composite Wing
}

\author{
Jiang $\mathrm{Xie}^{1, \mathrm{a}}$, Zhichun Yang ${ }^{2, \mathrm{~b}}$, Shijun Guo ${ }^{3, \mathrm{c}}$ \\ ${ }^{1,2}$ Northwestern Polytechnical University, Xi'an, 710072, P.R.China \\ ${ }^{3}$ Cranfield University, Bedfordshire, MK43 OAL, UK \\ a xiejiang5@msn.com, b yangzc@nwpu.edu.cn, ${ }^{c}$ s.guo@cranfield.ac.uk
}

Keywords: trim optimization; adaptive wing; active aeroelastic wing; aeroelastic tailoring; induced drag.

Abstract. This paper investigates aeroelastic tailoring and optimal trailing edge control surface deflection to minimize induced drag for a HALE UAV flying wing configuration. The analysis process is conducted on the Finite Element(FE) model of a composite slender wing. Genetic Algorithm(GA) is employed to aeroelastically tailor the wing by setting the composite ply orientation. The study examined conformal and traditional flaps and explored two optimization formulations to minimize drag. The impacts of the conformal control surface are recognized as required deflection saving which can be translated to drag reduction. The results also show that the control demands for the optimal trim can be further reduced if the wing is properly tailored.

\section{Introduction}

To improve the UAV performance, many innovative technologies have been proposed and are still under development. The adaptive wing concept emerged decades ago was one of those. Two test-beds, ATF/F-111 and F/A-18 were employed to demonstrate the innovative concepts which are Mission Adaptive Wing (MAW) technique and Active Aeroelastic Wing (AAW) technology respectively. The former varies the camber with smooth seamless contour with sophisticated mechanism on leading and trailing edge instead of conventional control surfaces with drag producing hinge and exposed mechanism [1]. Whereas, the later enhances the roll control authority by using the aeroelastic effect to actively twist the flexible wing with intentionally reduced stiffness rather than passive avoiding elastic deformation, normally resulting in weight penalty, like what the conventional design philosophy does [2].

The explorations of the combination of MAW and AAW technology have been found in recent literatures. A UAV with a seamless aeroelastic wing (SAW) [3] and a seamless rudderless fin [4] was designed to demonstrate the active aeroelastic wing technology. A PID control law was designed for the SAW to actively achieve the maximum roll performance [5]. To increase the aeroelastic stability and enhance the control effectiveness in the SAW study, aeroelastic tailoring has also been conducted based on previously developed methodology and design tools [6,7]. It was reported in the attractive research [8] that either using the active control surfaces or the laminate tailoring to make spanwise lift distribution as close to elliptical as possible, the induced drag can be reduced. Moreover, if the structure was properly tailored, the minimum drag can be obtained by the smallest deflection of conformal control surfaces.

This paper presents an investigation into utilization of multiple control surfaces to achieve optimum trim of a tailless HALE UAV. The differences in aerodynamic characteristics between the conformal control surface and the conventional one were examined at first. And then, the longitudinal trim was achieved with minimized induced drag by an optimum set of control surface deflections. The attention was also paid to taking advantage of aeroelastically tailoring the composite wing to save actuation energy. 


\section{Theoretical Background and Methodology}

\section{Longitudinal Trim Achieved by Elliptical Lift Distribution.}

A flying wing during cruise not only generates the required lift but also sustains the pitching moment equilibrium. The pitching moment of the aircraft about center of gravity (c.g.) is composed of the moment at aerodynamic center (a.c.) and the moment due to the lift acting at the a.c.

In order to minimize the induced drag, the required lift is desired to distribute as close to ellipse as possible. Eq. 1 is created to define the elliptical lift distribution achieved by the contributions from control surfaces, angle of attack and zero angle of attack lift mainly from built-in geometric twist, camber and aerodynamic twist etc. Eq. 2 describes the longitudinal moment equilibrium about c.g.. All derivatives, say $\left[\mathrm{Cl}_{i \delta j}\right],\left\{\mathrm{Cl}_{i \alpha}\right\},\left[\mathrm{Cm}_{i \delta j}\right]$, in this study are obtained by using MSC.Nastran 144 solver. The optimal control surfaces setting for a tailless aircraft longitudinal trim with the elliptical lift distribution can be therefore determined by these two equations.

$$
\begin{aligned}
& \left\{C l_{i_{-} \text {ellip }}\right\}=\left[C l_{i \delta j}\right]\left\{\delta_{j}\right\}+\left\{C l_{i \alpha}\right\} \alpha \\
& C l \times S M=\frac{2}{\overline{S c}}\left(\left\lfloor c_{i} \Delta y_{i}\right\rfloor\left[C m_{i \delta j}\right]\left\{\delta_{j}\right\}+\left\lfloor c_{i}\left(X a c-X a c_{i}\right) \Delta y_{i}\right\rfloor\left\{C l_{i_{-} e l l p}\right\}\right)
\end{aligned}
$$

\section{Aeroelastic Tailoring For Optimal Trim.}

Static aeroelastic tailoring of the wing structure for the optimum trim is conducted using Genetic Algorithm (GA) in Matlab environment. The laminate ply orientations of the composite wing box in all spanwise sections are selected as design variables. There are four optional ply angles: $0^{\circ}, 90^{\circ}$, $45^{\circ},-45^{\circ}$ because of their common employment in practical aircraft structures.

Two optimization schemes are attempted to find the better way of achieving the optimum trim associated with minimum induced drag. For the first formulation, scheme-A, the objective function is to approximate spanwise elliptical lift distribution translating to minimum induced drag under a certain dynamic pressure. Once the wing is aeroelastically tailored, the trimmed flight can be obtained by actuating the control surfaces at a little cost of drag. For the second formulation, scheme-B, the objective function is to minimize the deviation from the trim equilibrium at a certain dynamic pressure. The control surfaces are then used to minimize the induced drag with trim refinement. The two optimization schemes are posed below:

Scheme-A: $\operatorname{Min}(\delta) \quad$ where $\delta=1 / e\left(\theta_{1}, \theta_{2}, \cdots, \theta_{n}\right)$

Scheme-B: $\operatorname{Min}(\mathrm{Cmcg})$ where $\operatorname{Cmcg}=\operatorname{Cmac}\left(\theta_{1}, \theta_{2}, \cdots, \theta_{n}\right)-C l_{\text {required }} \times S M$

Design variables: ply angles $\theta_{1}, \theta_{2}, \cdots, \theta_{n}$

Subject to $V_{\infty}=V_{\text {examined }}, \theta_{i} \in\left[\begin{array}{llll}0^{\circ} & 90^{\circ} & 45^{\circ} & -45^{\circ}\end{array}\right]$

\section{Tailless HALE UAV Example}

A HALE UAV in flying wing configuration with full span conformal control surfaces is taken as the example platform in following studies. The aspect ratio, full span and area of the wing is $25,36 \mathrm{~m}$ and $51 \mathrm{~m}^{2}$ respectively. The sweptback angle of leading edge is $15 \mathrm{deg}$. The root chord is $1.6 \mathrm{~m}$ and the taper ratio is 0.8 . The finite element model of semi-span wing box representing structure and aerodynamic surface are shown in Fig.1. The box beam consists of 1676 structural shell elements and the lift surface is meshed into 270 aerodynamic elements (18 in spanwise and 15 in chordwise). The wing is manufacture by laminate composites, material properties of which including $E_{11}, E_{22}, v_{21}, G_{12}$, $G_{23}, G_{13}$ and $\rho$ are $163 \mathrm{GPa}, 10 \mathrm{GPa}, 0.28,5 \mathrm{GPa}, 5 \mathrm{GPa}, 5 \mathrm{GPa}$ and $1570 \mathrm{~kg} / \mathrm{m}^{3}$ respectively. Each span station is configured with a trailing edge control surface of 1 meter length. This slender wing box is divided into inner wing, middle wing and outer wing. In order to reduce the computation cost of optimization, the skin of each part consists of 16 plies stacked symmetrically. The initial layups and corresponding skin thicknesses are listed in table 1. 
Table 1 initial layups

\begin{tabular}{|c|c|c|c|}
\hline & Layups[deg] & Range[m] & $\begin{array}{c}\text { Equivalent skin Thickness/ } \\
\text { thickness per ply[mm] }\end{array}$ \\
\hline Inner & {$[0,45,-45,90,0,45,-45,90] \mathrm{s}$} & {$[0,8]$} & $45 / 2.8125$ \\
\hline Middle & {$[0,45,-45,90,0,45,-45,90] \mathrm{s}$} & {$[8,13]$} & $40 / 2.5$ \\
\hline Outer & {$[0,45,-45,90,0,45,-45,90] \mathrm{s}$} & {$[13,18]$} & $25.6 / 1.6$ \\
\hline
\end{tabular}

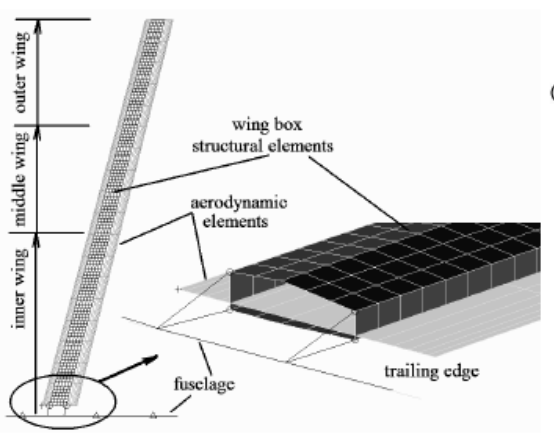

Fig. 1 FE model of the wing box
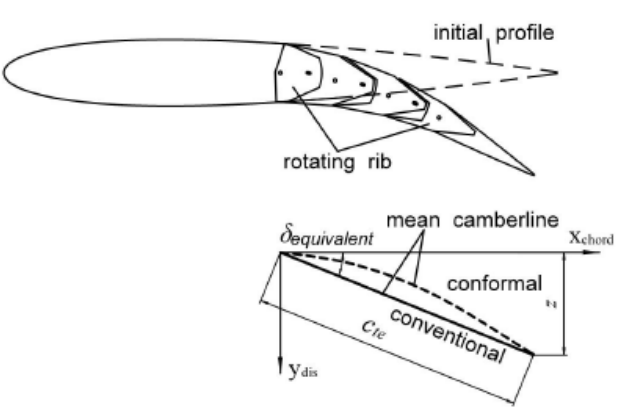

Fig. 2 Rotating rib concept

A conceptual design based on the rotating rib as shown in Fig.2, proposed by H.Mooner [9] is employed to implement the variable camber adaptive wing concept for the current HALE UAV. The rib structure can be simplified as a leverage system with single degree of freedom. This system enables trailing edges to vary camber smoothly and seamlessly without abrupt change on airfoil geometry.The mean camber line of the conformal control surface configured with rotating rib is represented by an equation of an arc of circle as shown in Eq. 3. Conventional control surfaces are concerned as well for the purpose of comparison. For all types of control surface, Eq. 4 defines the deflection angle which is the arc tangent value of the trailing edge chord $c_{t e}$ over the displacement $z$ on the trailing edge ending point.

$$
\begin{aligned}
& y_{\text {dis }}=\frac{1}{2}\left(z+\frac{c_{t e}^{2}}{z}\right)-\sqrt{\frac{1}{4}\left(z+\frac{c_{t e}^{2}}{z}\right)-x_{\text {chord }}{ }^{2}} \\
& \delta=\arctan \left(\frac{c_{\text {te }}}{z}\right)
\end{aligned}
$$

\section{Analysis Results}

\section{Aerodynamic and Aeroelastic Characteristics.}

The pressure distribution over the wing tip section with these two types control surfaces are shown in Fig. 3. Two flap-to-chord ratios $60 \%$ and $30 \%$ were concerned to close examine the aerodynamic characteristics evaluated at $\alpha=5.73^{\circ}, \delta=10^{\circ}$ and dynamic pressure $q=50 \mathrm{~Pa}$. The two-dimensional analysis shows the relationship between the chordwise pressure distribution and the airfoil geometry especially the effects of trailing edge. The marked difference in the pressure distribution is in the area around and aft of the hinge line. The hinged surface shows the classic pressure peak caused by the violent change in the direction of flow. On the other hand, the pressure distribution on the conformal control surface reaches a maximum behind the hinge line, but does not have a pressure peak associated with it. The elastic axis for a flexible wing is typically around $30-40 \%$ chord from leading edge, and the pressure distribution produced by the conformal control surface will result in a larger pitching down moment about the elastic axis. 


\section{Results of Different Aeroelastic Tailoring Schemes.}

The UAV composite wing structure is optimized for minimum drag trim by using the two schem introduced earlier. The optimal ply orientations are shown in Table 2. The results for scheme-A sho that the inner wing has been tailored to be washin laminates while the outer wing behaves lil washout laminates. The contribution of this tailoring can be inspected from the pressure distributic over tailored wing is closer to ellipse than that of untailored wing in Fig.4. The induced drag 0.00460 and 0.00472 on the scheme-A tailored wing and untailored wing respectively and tl minimum induced drag obtained by elliptical lift distribution is 0.00435 . Whereas, the strong washo twist attributed to more $45^{\circ}$ plies is required over the whole span in order to obtain the pitching I moment arising from wing tip deformation when the scheme-B has been implemented. This can 1 observed from Fig. 4 where the lift decreases quickly from inner to outer wing. The resultant pitchir moment about C.G. on scheme-B tailored wing is $0.055 \mathrm{Nm}$ which means the moment equilibrium $\mathrm{h}$ : been almost approached by utilizing the wing deformation without control surface contribution However, the highest induced drag coefficient will be paid for this scheme which is 0.005 .

Table 2 optimal results

\begin{tabular}{|c|c|c|}
\hline & Scheme-A & Scheme-B \\
\hline Inner & {$[-45,-45,45,45,0,90,-45,-45] \mathrm{s}$} & {$[45,0,45,45,45,45,45,0] \mathrm{s}$} \\
\hline Middle & {$[0,90,0,0,0,0,0,90] \mathrm{s}$} & {$[0,45,0,45,45,45,45,0] \mathrm{s}$} \\
\hline Outer & {$[90,45,45,0,90,45,0,90] \mathrm{s}$} & {$[45,45,0,0,45,45,45,0] \mathrm{s}$} \\
\hline
\end{tabular}

The control surfaces set to trim the UAV and achieve minimum induced drag are estimated at then compared between tailored and untailored wing. In the case of scheme-A as shown in Fig.5, bo control surface deflections and angle of attack have been reduced on the tailored wing in trim wi $\mathrm{SM}=0.25$. Since more lift distributes over inner wing in the case of scheme-B in Fig.6, the contr surfaces have to be deflected up to reduce lift to match the desired distribution rather than deflectic down of untailored wing due to insufficient lift. However the only method to compensate the lift lo due to washout is to increase the angle of attack, around 3 degree more in this case, at the cost of lar: drag.

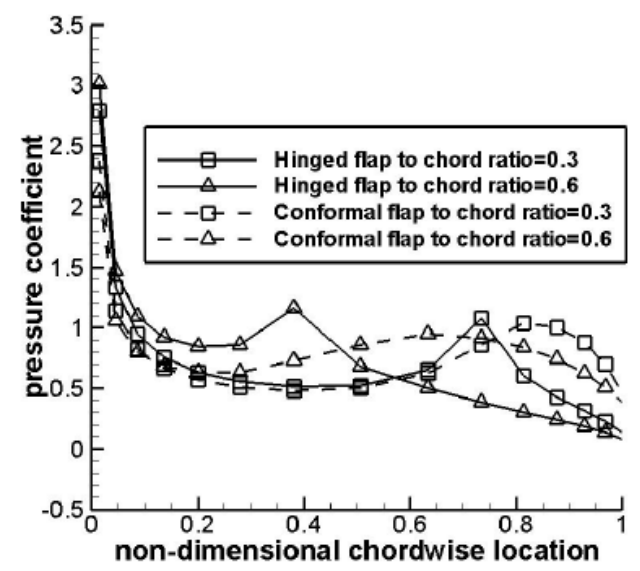

Fig. 3 Pressure over wing tip section

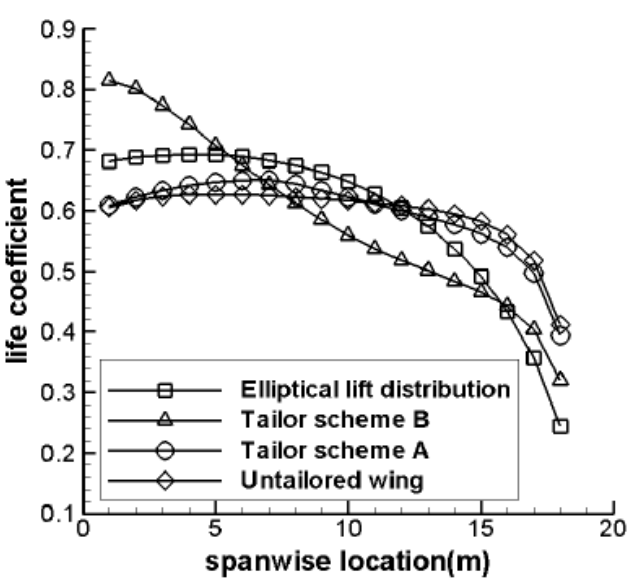

Fig. 4 Spanwise Lift Distribution 


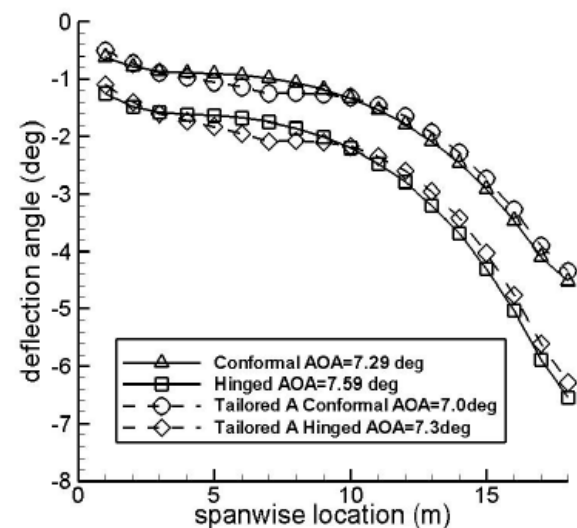

Fig. 5 Scheme-A at $\mathrm{SM}=0.25$

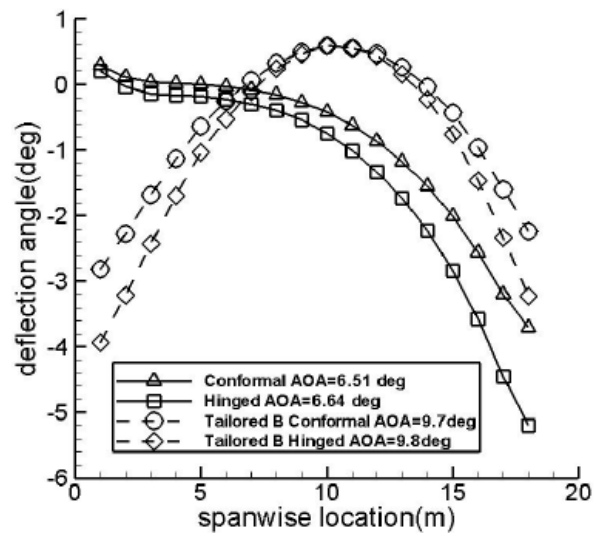

Fig. 6 Scheme-B at $\mathrm{SM}=0.2$

\section{Conclusions}

The following conclusions are drawn from this investigation for a tailless UAV trim.

1) Longitudinal trim could benefit from elliptical lift distribution by shifting the lift inboard which yields pitching up moment to offset the pitching down moment from outer wing.

2) The required deflection from the conformal trailing edge control surfaces for trim is apparently less than the conventional hinged ones. Thus, the former design has the potential of profile drag reduction to improve the HALE UAV performance.

3) By aeroelastic tailoring of a flexible wing structure, an optimal wing deformation can result in a nearly elliptical lift distribution and reduce the induced drag. This design scheme appears to be particularly effective at high subsonic regime where aeroelastic effects are more pronounced. Combined with the tailored wing, small actuated deflections of the conformal trailing edge control surfaces can further reduce the induced drag without compromising the trim.

4) The aeroelastic tailoring scheme-A can reduce the angle of attack as well as control surface deflection without lift lost due to washin over inner wing. The scheme-B results in larger trailing edge control surface deflections and angle of attack as a penalty arising from large washout twist of the wing.

\section{References}

[1] Gilbert, W., "Mission Adaptive Wing System for Tactical Aircraft," Journal of Aircraft, Vol.18, No.7, 1981, pp.597-602.

[2] Pendelton, E., et.al., "The-53 A Summary of the Active Aeroelastic Wing Flight Research Program", AIAA Paper No.2007-1855, April 2007.

[3] Perera, M., Guo, S., "Optimal Design of a Seamless Aeroelastic Wing Structure," AIAA paper 2009-2195, May 2009.

[4] Trapani, M., Guo, S., "Design and analysis of a rudderless aeroelastic fin," Journal of Aerospace Engineering, Vol.223, No.6, 2009, pp. 701-710.

[5] Yang, D., Guo, S., "Rolling Active control for an Aircraft of Seamless Aeroelastic Wing," AIAA paper 2009-2197, May 2009.

[6] Guo, S., "Aeroelastic Optimisation of an aerobatic aircraft Wing Structure," Aerospace Science and Technology, No.11, 2007, pp.396- 404.

[7] Guo, S., Chen, W., and Cui, D., "Aeroelastic Tailoring of Composite Wing Structures by Laminate Layup Optimisation," AIAA Journal, Vol. 44, 2006, pp.3146-3149.

[8] Weisshaar, T., Duke, K., "Induced Drag Reduction Using Aeroelastic Tailoring with Adaptive Control Surfaces,” Journal of Aircraft, Vol.43, No.1, 2006, pp.157-164.

[9] Monner, H., "Realization of an optimized wing camber by using form variable flap structures," Aerospace Science Technology, Vol.5, No.7, 2001, pp.445-455. 